1987). El hábitat de esta especie lo constituyen roquedos ácidos, muy húmedos y umbrosos (Laínz, 1986; Navas et al., 1998).

Vandenboschia speciosa se distribuye por el oeste de Europa y Macaronesia. En la Península Ibérica se encuentra en la cornisa cantábrica y en las sierras de Algeciras (Salvo, 1990; Laínz,1986). Es una especie vulnerable según el Catálogo Andaluz de Especies de la Flora Silvestre Amenazada (decreto 104/1994, BOJA núm. 197, pg 7948). En la Península Ibérica y en general en su área de distribución se considera un helecho raro, necesitando para su supervivencia una vigilancia contínua (Salvo, 1990).

\section{BIBLIOGRAFÍA}

CABEZUDO, B. y A.E. SALVO -1987Vandenboschia, en Valdés, B., S. Talavera y E. Fernández Galiano (eds.) Flora Vascular de Andalucía Occidental. I: 58. Ed. Ketres. Sevilla.
LAÍNZ, M. -1986- Vandenboschia, en Castroviejo et al. (eds.): Flora Iberica, I:75

NAVAS, P., A.V. PÉREZ LATORRE, Y. GIL., D. NAVAS y B. CABEZUDO -1998- Datos sobre biología y conservación de algunos pteridófitos relícticos del Campo de Gibraltar. Almoraima 19: 199-208-

SALVO, E. -1990- Guía de Helechos de la Península Ibérica y Baleares. Ediciones Pirámide. S.A. Madrid.

Aceptado para su publicación en Enero de 1998

Dirección de las autoras. Dpto. de Biología Vegetal y Ecología. Apdo. 1095, 41080 Sevilla. España.

\title{
45. ACERCA DEL GÉNERO ISOETES (ISOETACEAE) EN ARAGÓN
}

\author{
José María MARTíNEZ, José Luis BENITO ALONSO y César PEDROCCHI
}

About the genus Isoetes (Isoetaceae) in Aragon.

Palabras clave. Isoetes velatum, Isoeto-Nanojuncetea, Teruel, Aragón.

Key words. Isoetes velatum, Isoeto-Nanojuncetea, Teruel, Aragon.

Las especies del género Isoetes son plantas de zonas húmedas que se comportan, bien como hidrófitos, bien como anfibios. En las zonas de montaña viven en los lagos (también denominados ibones) y en tierra baja en lagunas que pueden ser temporales o permanentes. Sin embargo, dichos ambientes han sido sistemáticamente destruidos. Así, los lagos de alta montaña del Pirineo han sido represados casi en su totalidad para aprovechamiento 
hidroeléctrico, mientras que las lagunas de tierra baja han sido desecadas por motivos sanitarios, para ganar terrenos de cultivo o simplemente han sido rellenadas con escombros y basura.

Estos pueden ser algunos de los motivos por los que hasta la fecha, el género Isoetes no se había localizado en Aragón (Castroviejo et al., 1986; Mateo, 1990; Villar et al., 1997), a pesar de existir especies de dicho taxon en las regiones vecinas.

Sin embargo, existes algunas citas que conviene aclarar. Para el Pirineo aragonés se insinúa la presencia de I. lacustris L. en el mapa de Bolòs y Vigo (1984: 146), en una zona que parece corresponder a la cabecera de los ríos oscenses Cinca y Ésera. No existen testimonios de herbario al respecto, así que probablemente tomaran la cita recogida por Cadevall (1937: 362) de Timbal-Lagrave, tal como más tarde harían Carreras et al. (1993: 35), del lago Basibé de Castanesa (Huesca). Dicha referencia debe corresponder en realidad al lago Baciver del valle de Arán (Lérida), puesto que ya Coste (1910: 441) aporta una cita aranesa de Timbal-Lagrave para dicho taxon de la siguiente e inequívoca forma: "Val d'Aran: grand lac de Bacivé, $2110 \mathrm{~m}$, au-dessus du rio Malo, entre les massifs du la Llanza et le Marimaña (Timbal ...)”. Esta cita aranesa ha sido confirmada recientemente por Gacia y Ballesteros (1998), aunque por desgracia dicha población ha sido extinguida. Además, es planta que no ha sido encontrada en el lago Basibé de Castanesa, tal como señalan Villar et al. (1997: 7).

Por otra parte, hace un par de años llegó al herbario JACA una muestra de un Isoetes cf. lacustris, supuestamente recolectado en el ibón de Estanés (Ansó, Huesca), con una etiqueta cuyos datos de cuadrícula y altitud no coincidían con las de dicho lago; estaba recogida presuntamente el verano de 1990, y tenía síntomas evidentes de "vejez". Dicho ibón fue represado en 1914 para abastecer de electricidad al valle francés de Aspe, y que más tarde alimentaría la línea de ferrocarril Canfranc-Oloron. Por tal motivo, estos momentos no hay comunidades de macrófitos acuáticos en dicho ibón, tal como ocurre en otros del Pirineo como el citado lago Baciver (valle de Arán, Lérida), donde toda la vegetación acuática sucumbió totalmente dos años después de la construcción de la presa (Gacia y Ballesteros, 1998). Se hace muy difícil pensar que dicha planta haya podido ser recolectada en la actualidad en el ibón de Estanés (al respecto de otras plantas sospechosas, véase Benedí y Sáez, 1996: 574).

Del resto de provincias aragonesas no tenemos constancia de mención alguna para este género.

\section{Isoetes velatum A. Braun subsp. velatum}

TERUEL: Odón, hacia Campillo de Dueñas, laguna, 1090 m, 30TXL1626, 10-VI1998, J.L. Benito, J.M. Martínez y C. Pedrocchi (JACA 523/98).

Primera cita para Aragón de este pteridófito localizado en los márgenes exondados de la laguna de Odón, sobre terreno arenoso silíceo.

En un inventario realizado en la misma fecha, sobre una superficie de $2 \mathrm{~m}^{2}$, la comunidad presenta un recubrimiento del 75 $\%$. Las especies características anotadas han sido: Isoetes velatum 2.1, Juncus pygmaeus + , Mentha cervina 3.3, Eleocharis palustris 1.2, E. acicularis +.2 y Elatine hexandra +.2 , acompañadas por Ranunculus saniculifolius 1.2, Polygonum arenastrum + y Juncus tenageia + .

Creemos que nuestro inventario puede encajar bien dentro de la asociación JuncoIsoetetum velatae Rivas Goday (1956) 1969 (Cicendion, Isoetalia, Isoeto-Nanojuncetea), comunidad anual de márgenes de lagunas que se conservan encharcados hasta principios de verano (Velayos et al., 1989: 26).

I. velatum subsp. velatum se distribuye en 
la Península Ibérica principalmente por el centro y oeste de la misma, faltando en el tercio norte. Las citas sorianas de Segura Zubizarreta et al. (1998: 30), junto con las alcarreñas recopiladas por Carrasco et al. (1997: 14), la valenciana de Mansanet y Mateo (1978), y la que aportamos aquí, cierran por el NE su distribución en la península, añadiéndose la gerundense cita disyunta de Font et al. (1995: 109).

Desde aquí queremos proponer la inclusión de Isoetes velatum subsp. velatum en el Catálogo de Especies Amenazadas de Aragón (Decreto 49/1995) en su anexo II (Especies de flora sensibles a la alteración de su hábitat), tanto por la rareza de la especie (dos centenares de ejemplares en la única población conocida en Aragón) como por la escasez y fragilidad del ambiente en el que vive; las pocas lagunas que quedan siguen estando amenazadas de roturación o desecación artificial, y son el único reducto para albergar este tipo de especies tan singulares y bien adaptadas a los ciclos irregulares de inundación-sequía.

AGRADECIMIENTOS. A D. Juan Lacasa de Jaca y $D^{a}$. Josefina Mendiara ex-alcaldesa de Ansó, que nos proporcionaron valiosos datos históricos sobre el ibón de Estanés.

\section{BIBLIOGRAFÍA}

BENEDÍ, C. y L. SÁEZ -1996- Propósitos y despropósitos de Reineck y sus prosélitos. Anales Jard. Bot. Madrid 54: 570-574.

BOLÒS, O. y J. VIGO -1984- Flora dels Països Catalans, vol. 1. Introducció. (LycopodiaceaeCapparaceae). Editorial Barcino. 736 pp. Barcelona.

CADEVALL, J. - 1937- Flora de Catalunya, vol. VI. Institut de Ciències. 445 pp. Barcelona.

CARRASCO, M.A., M.J. MACÍA y M. VELAYOS -1997- Listado de plantas vasculares de Guadalajara. Monografías de Flora Montiberica. 208 pp. Valencia.
CARRERAS, J., E. CARRILLO, J.M. NINOT, R.M. MASALLES y J. VIGO -1993- El poblament vegetal de les valls de Barravés i de Castanesa. I-Flora i vegetació. Acta Bot. Barcin. 42: 1-392.

CASTROVIEJO, S. et al. Eds. -1986- Flora iberica, vol. I. Real Jardín Botánico, C.S.I.C. Madrid. COSTE, H. -1910- Catalogue des plantes des Pyrénées. Inédito. 445 pp.

DECRETO 49/1995 de 28 de marzo, de la Diputación General de Aragón, por el que se regula el Catálogo de Especies Amenazadas de Aragón. Bol. Oficial Aragón 42: 1270-1275.

FONT, J., L. VILAR, X. VIÑAS y I. SORIANO 1995-Isoetes velata A. Br. i I. setacea Lam. a l'Alt Empordà. Butll. Inst. Cat. Hist. Nat. 62 109-114.

GACIA, E. \& E. BALLESTEROS -1998- Effects of building up a dam in a shallow mountain lake (Baciver, Central Pyrenees). Oecologia Aquatica 11: 55-66.

MANSANET, J. y G. MATEO -1978- Sobre la vegetación de la clase Isoeto-Nanojuncetea en la provincia de Valencia. Anales Inst. Bot. Cavanilles 35: 219-223.

MATEO, G. -1990- Catálogo florístico de la provincia de Teruel. Instituto de Estudios Turolenses. 554 pp. Zaragoza.

SEGURA ZUBIZARRETA, A., G. MATEO y J.L. BENITO ALONSO -1998- Catálogo florístico de la provincia de Soria. Monografías de Flora Montiberica, $\mathrm{n}^{\circ} 4.531 \mathrm{pp}$. Valencia.

VELAYOS, M., M.A. CARRASCO y S. CIRUJANO -1989- Las lagunas del Campo de Calatrava (Ciudad Rea!). Bot. Complutensis 14: 9-50.

VILLAR, L., J.A. SESÉ Y J.V. FERRÁNDEZ 1997- Atlas de la Flora del Pirineo Aragonés, I (Introducción. Lycopodiaceae-Umbelliferae). Consejo de Protección de la Naturaleza (D.G.A.) e Instituto de Estudios Altoaragoneses. XCI+648 pp. Huesca.

Aceptado para su publicación en Noviembre de 1998

Dirección de los autores. Instituto Pirenaico de Ecología, C.S.I.C. Apdo. 64. E-22700 JACA (Huesca).C.e.: jolube@ipe.csic.es 